\title{
One-stage surgical excision of a huge bilateral multiple osteochondroma of the hip: a case report
}

\author{
Afshin Taheriazam ${ }^{1}$, Amin Saeidinia ${ }^{2}$
}

${ }^{1}$ M.D., Assistant Professor, Department of Orthopedics Surgery, Tehran Medical Sciences Branch, Islamic Azad University, Tehran, Iran

${ }^{2}$ M.D., Assistant Researcher, Medical Faculty, Mashhad University of Medical Sciences, Mashhad, Iran

Type of article: Case report

\begin{abstract}
Osteochondroma or hereditary multiple exostoses is the most common benign bone tumor and is usually found in young patients. Osteochondromata of the proximal femur or hip have been reported in $30 \%$ to $90 \%$ of patients with hereditary multiple exostoses. This article presents a 25 -year-old-male referred to our orthopedic clinic with a complaint of pain in both groins for the last four years which has deteriorated in the past 6 months by limitation of range of motion. Radiographic findings were consistent with huge hip osteochondroma and a histopathological report confirmed the diagnosis. This was a case of a huge bilateral osteochondroma of the hip originating from the posterior of the hips to the neck of the femur and hip joints and part of proximal of femur, that underwent one-stage surgical excision of the tumor with posterior approach and tumor resection. As we know, this case of bilateral huge hip osteochondromas has rarely been presented previously by someone who has undergone onestage surgery treatment of a tumor this size. Bilateral hip osteochondroma is a rare condition and we showed that one-stage excision can be performed successfully.
\end{abstract}

Keywords: Osteochondroma, One-stage bilateral excision, Hereditary multiple exostosis

\section{Introduction}

Hereditary multiple exostosis (HME), is a type of rare benign bone tumor and is an inherited autosomal dominant disorder characterized by the presence of multiple exostoses or osteochondromas (1). Osteochondroma is a cartilage capped bony projection arising on the external surface of the bone, containing a marrow cavity that is continuous with that of the underlying bone (2). It is generally developed during the first decade of life and stopped growing when the individual gained skeletal maturity (3). Although frequency and presence of osteochondroma can be difficult to characterize because of its asymptomatic nature, it can be found as a palpable mass which may cause pain due to fracture through a pedunculated stalk, overlying bursal inflammation or impingement on an overlying structure (4). The radiological pathognomonic characteristic of this tumor is the cortical and marrow continuity of the lesions with the adjacent bone (5). The lesions may be solitary or multiple, the latter forming part of the hereditary multiple exostoses syndrome (6). These lesions may also appear with complications such as bone deformities, fractures $(5,7)$, neurological or vascular compromise $(5,8,9)$, bursa formation and more rarely, malignant transformation $(10,11)$. It is possible to diagnose multiple osteochondroma (MO) when at least two osteochondromas of the juxta-epiphyseal region of long bones are observed through radiology (6). In the majority of patients diagnosed with MO, a positive family history mutation in one of the EXT genes can be detected (6). With an estimated prevalence of 1 per 50,000 individuals within the general population (12), it appears to be higher in males than in females (male/female ratio 1.5:1) (13). In this case report we presented a bilateral hip multiple osteochondroma with huge size in a 25 -year-old male patient without family history of osteochondroma or HME, who required surgical treatment.

\section{Corresponding author:}

Assistant Professor Dr. Afshin Taheriazam, Tehran Medical Sciences Branch, Islamic Azad University, Khaghani St, Shariati Ave, Tehran, Iran. Tel: +989121113486, Fax: +982188033020, Email: afshintaheriazam@yahoo.com Received: September 21, 2016, Accepted: May 12, 2017, Published: September 2017

iThenticate screening: January 03, 2017, English editing: August 06, 2017, Quality control: September 12, 2017

(C) 2017 The Authors. This is an open access article under the terms of the Creative Commons Attribution-NonCommercialNoDerivs License, which permits use and distribution in any medium, provided the original work is properly cited, the use is non-commercial and no modifications or adaptations are made. 


\section{Case Presentation}

A 25 year-old male with complaints of severe swelling and pain in both hips for the past 12 months was referred to Erfan Hospital, Tehran, Iran in May 2015. He noted that the swelling of both hips had insidious onset and gradually increased in size over a period of 4 years. Patient also mentioned that his aching was continuous pain, aggravated by activities and relieved by rest and analgesics. His pain was radicular to the lower extremities by activity. His daily activities were significantly restricted due to the mass effect of the tumor which restricted movement of the hip joint. He had problems in walking and other motions related to the hip joints activities. In the recent 6 months before admission, his chief complaint was in sitting. He suggested no manifestation of discharge or redness. There was no history of trauma or fever. Skeletal survey showed other evidence of similar lesions in the patient; however, they were smaller and did not cause problems for him. They were in the proximal of tibia, the distal of femur, the proximal of humorous and in the scapula. He had no history of malignancy or known skeletal disorders in his family. He was a smoker but he did not use opium or alcohol. The patient had no risk factor of tendency to the malignancy. He had no history of previous similar mass in the past. He had no history of activity limitation in childhood or adolescence. He did not use drugs and had no history of sensitivity to any substance or drug. On examination, the patient had no evidence of any systemic illness. He had a limitation in range of motion with $30^{\circ}$ flexion and $10^{\circ}$ abduction in the hip joints. Local examination revealed two diffused, ill-defined, hard, globular swellings of about $30 \times 25 \mathrm{~cm}$ in the left hip and $40 \times 30 \mathrm{~cm}$ in the right hip. They were found and aroused posterior of the hips to neck of femur and hip joints and part of proximal of femur. Surface was irregular, hard in consistency with ill-defined borders. Skin over the swelling was normal. It was not warm. There was no localized lymphadenopathy and distal neurovascular deficit. There was no evidence of any laboratory abnormalities. Plain radiographs (Figure 1), CT scan (Figure 2), three-dimensional CT scan (Figure 3) and MRI (Figure 4) were done, and reports suggested it to be a huge multiple osteochondroma or hereditary multiple exostoses. As it is seen on 3D CT and MRI, it had a sessile structure and extended outward broadly in the region of neck of femur, hip joint and lesser and greater trochanter in both sides. So we decided to perform a one-stage complete excision of both hips, and a frozen section evaluation of the tumor was made. The patient was located in supine position. We performed two incisions simultaneously in both posterior of hips. A posterior trans-gluteal approach with splitting of gluteus maximus was used and the sciatic nerve was explored in both sides (Figure 5). After complete dissection of the tumor, it was removed en masse in both sides. There was no evidence of local invasion in either side. We performed frozen section during the operation and it confirmed that there was no evidence of malignancy or tumoral cells. The excised tumor was sent to pathology laboratory and it was diagnosed osteochondroma. Then we closed and sutured the tumor sites (Figure 6). General anesthesia was used for this procedure and the operation lasted approximately 1:40 minutes. The patient maintained partial weight bearing for a period of four weeks. After 6 weeks, the patient was able to return to his daily routine activities. The patient continued to receive follow-up treatment once every two months for six months and then once every six months up to the present. At the last follow-up, the patient was completely asymptomatic and the radiographs and MRI showed no evidence of local recurrence. He did not have any dislocation, dysplasia or other signs in radiological follow-ups.
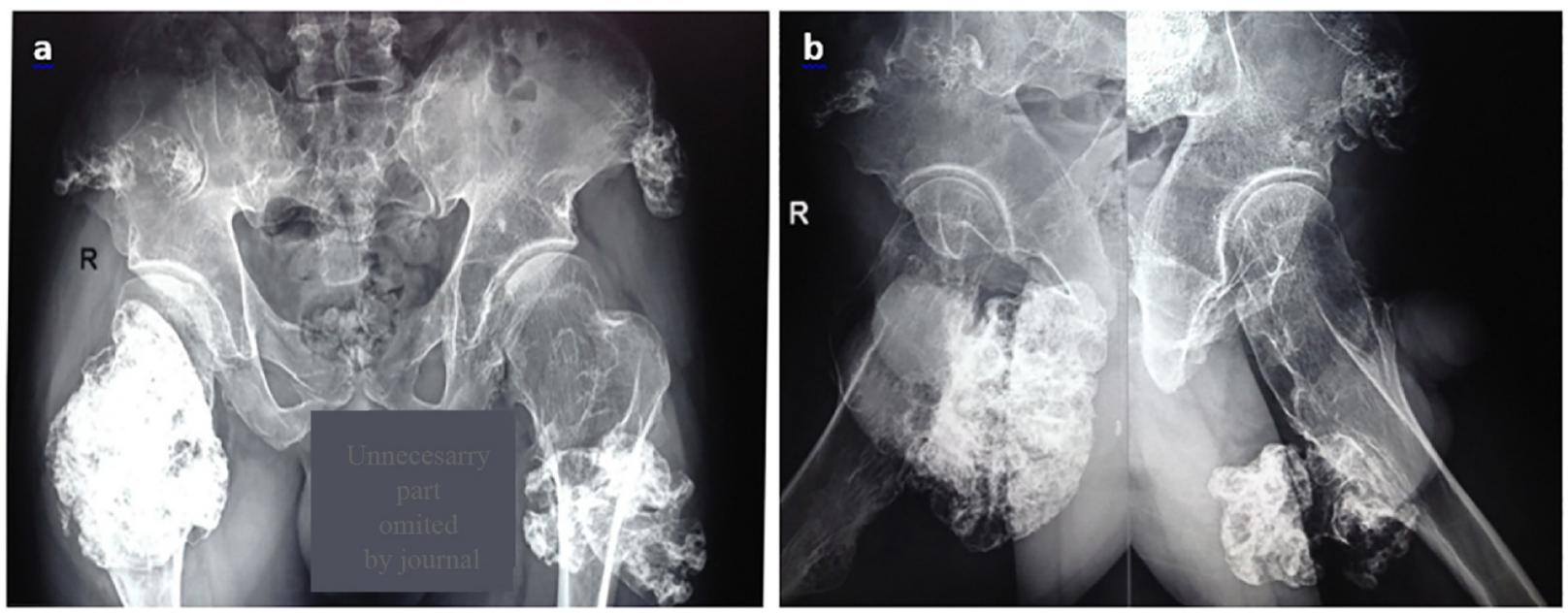

Figure1. Plain radiograph of pelvis showed bilateral cauliflower like mass attached to femoral neck and expands to proximal of femur and posterolateral direction; a. AP view. b. Lateral view 


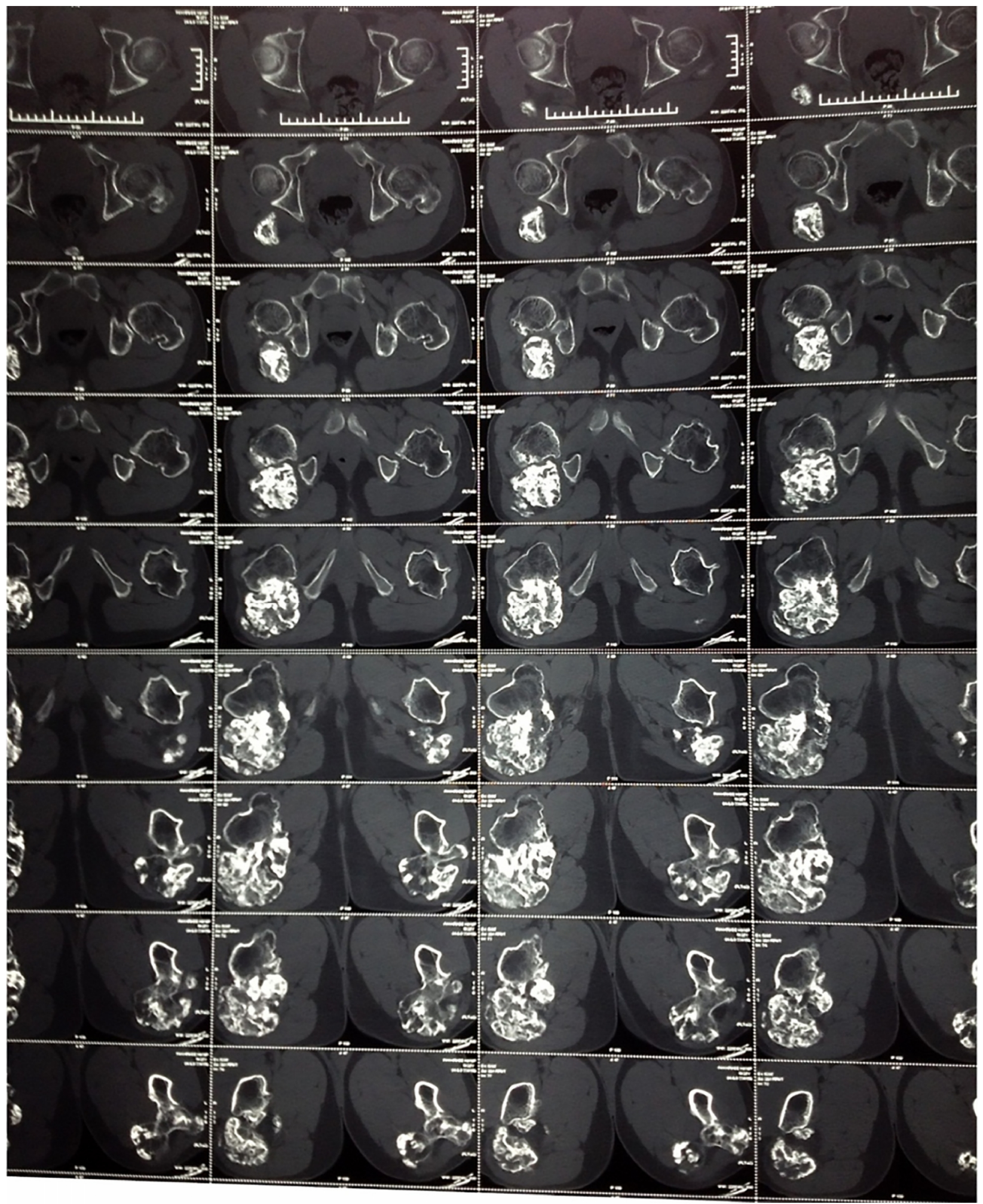

Figure 2. Multi Slice Computed Tomography of the hip demonstrates mass originating from posterior of the hips to neck of femur and hip joints and part of proximal of femur without any soft tissue extension and malignant degeneration. 


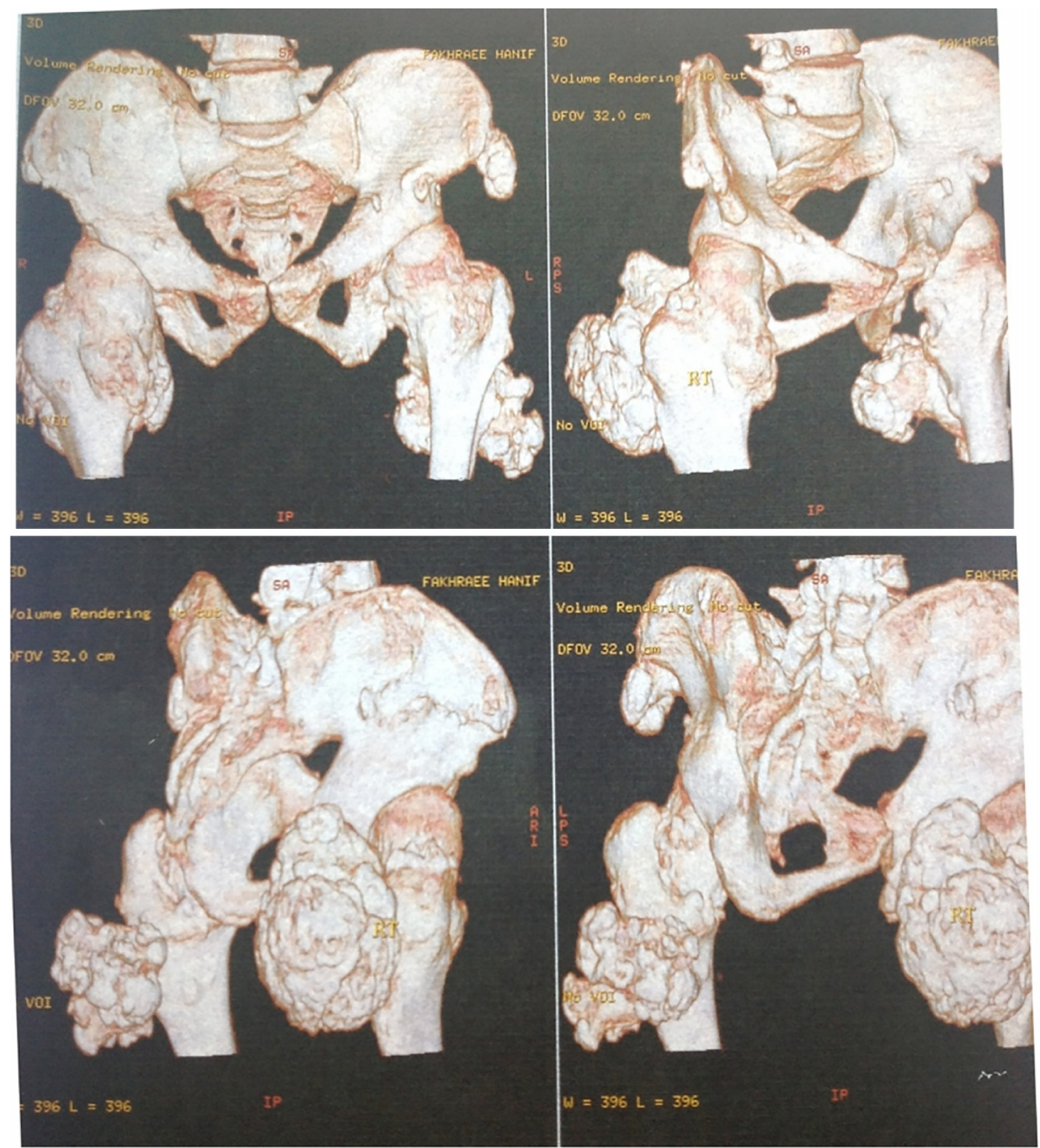

Figure 3. CT three-dimensional reconstruction of the pelvis showing multiple osteochondromata in both hips.
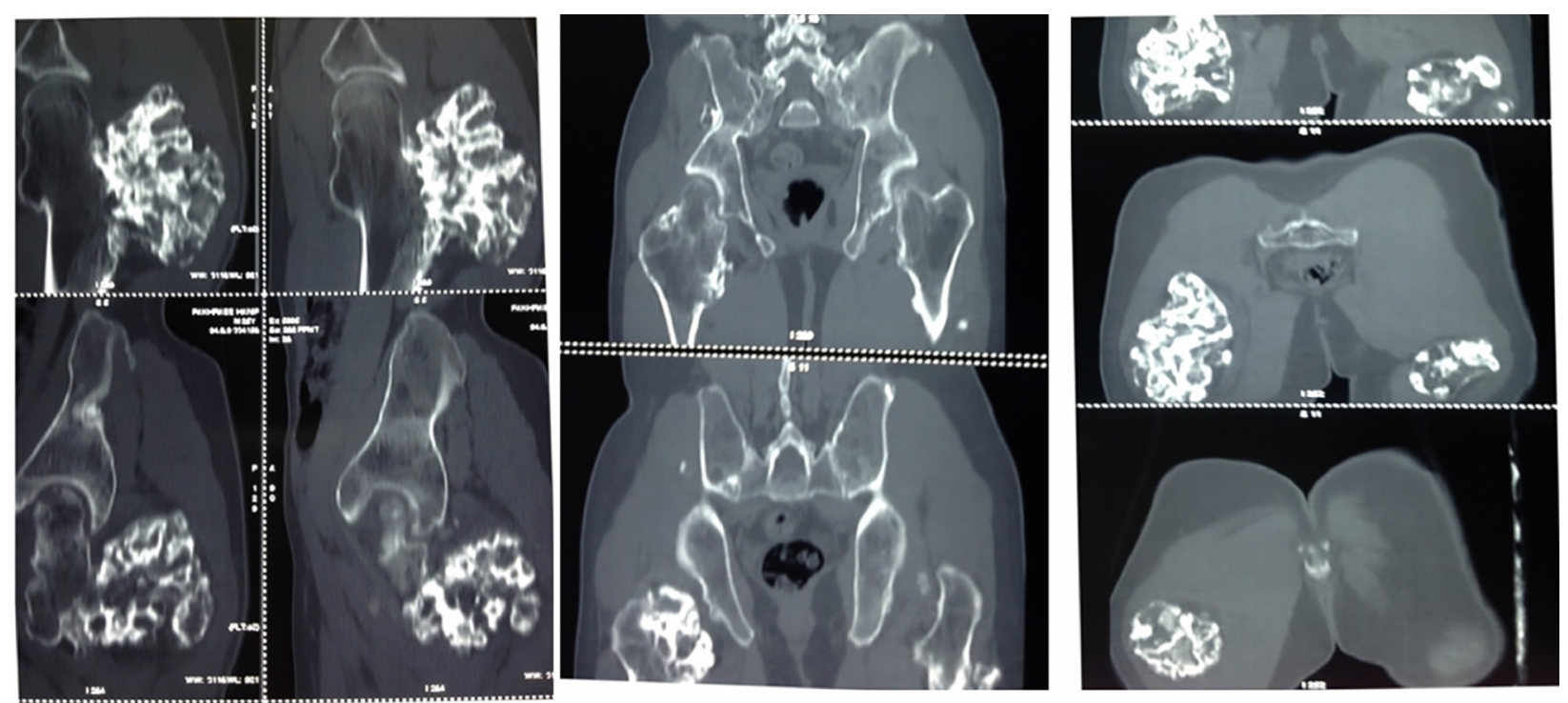

Figure 4. MRI of the hip with both sides mass originating from posterior of the hips without any soft tissue extension and malignant degeneration but displacement of the adjacent muscle and sciatic nerve. 

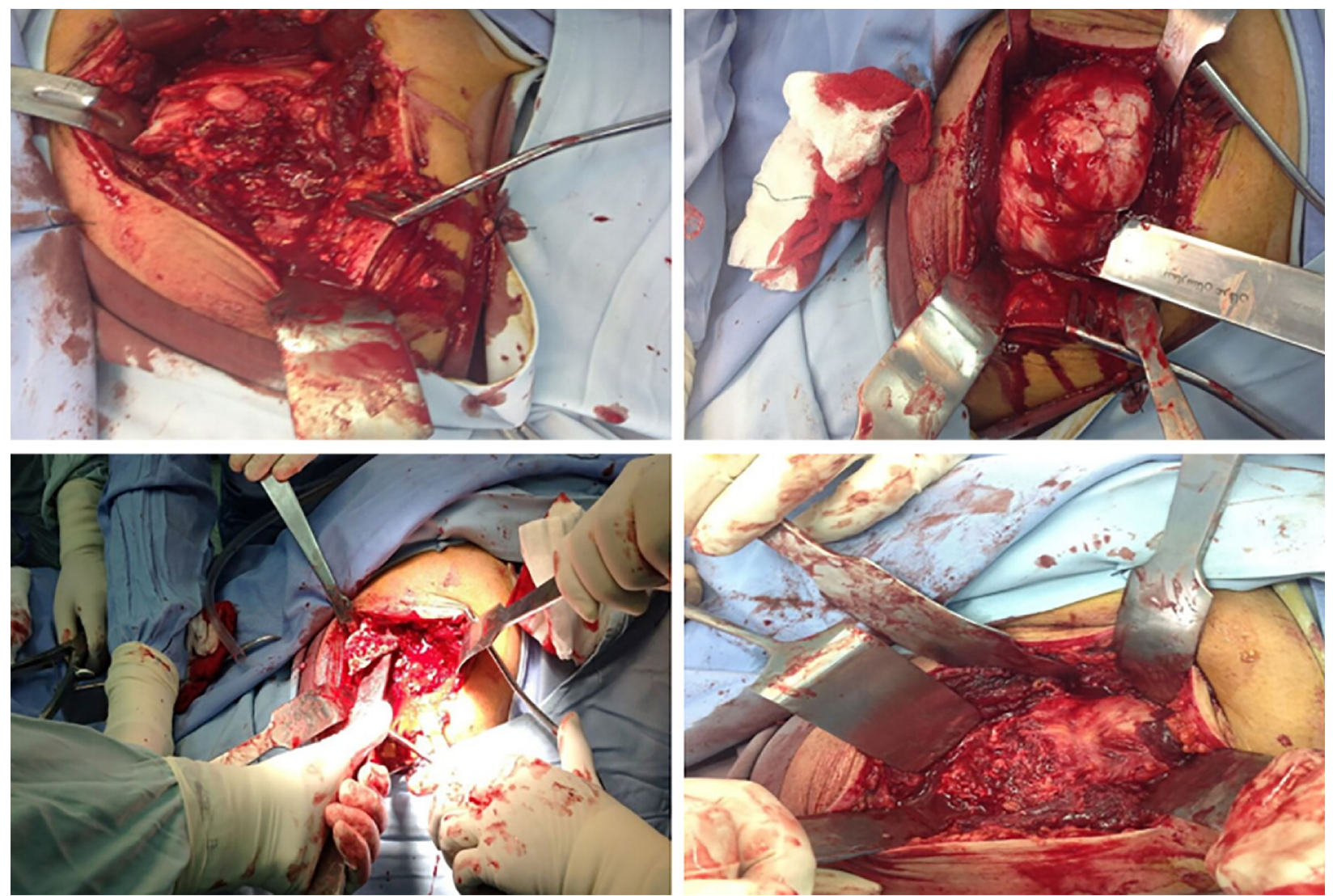

Figure 5. Showing surgical resection performed through posterolateral approach
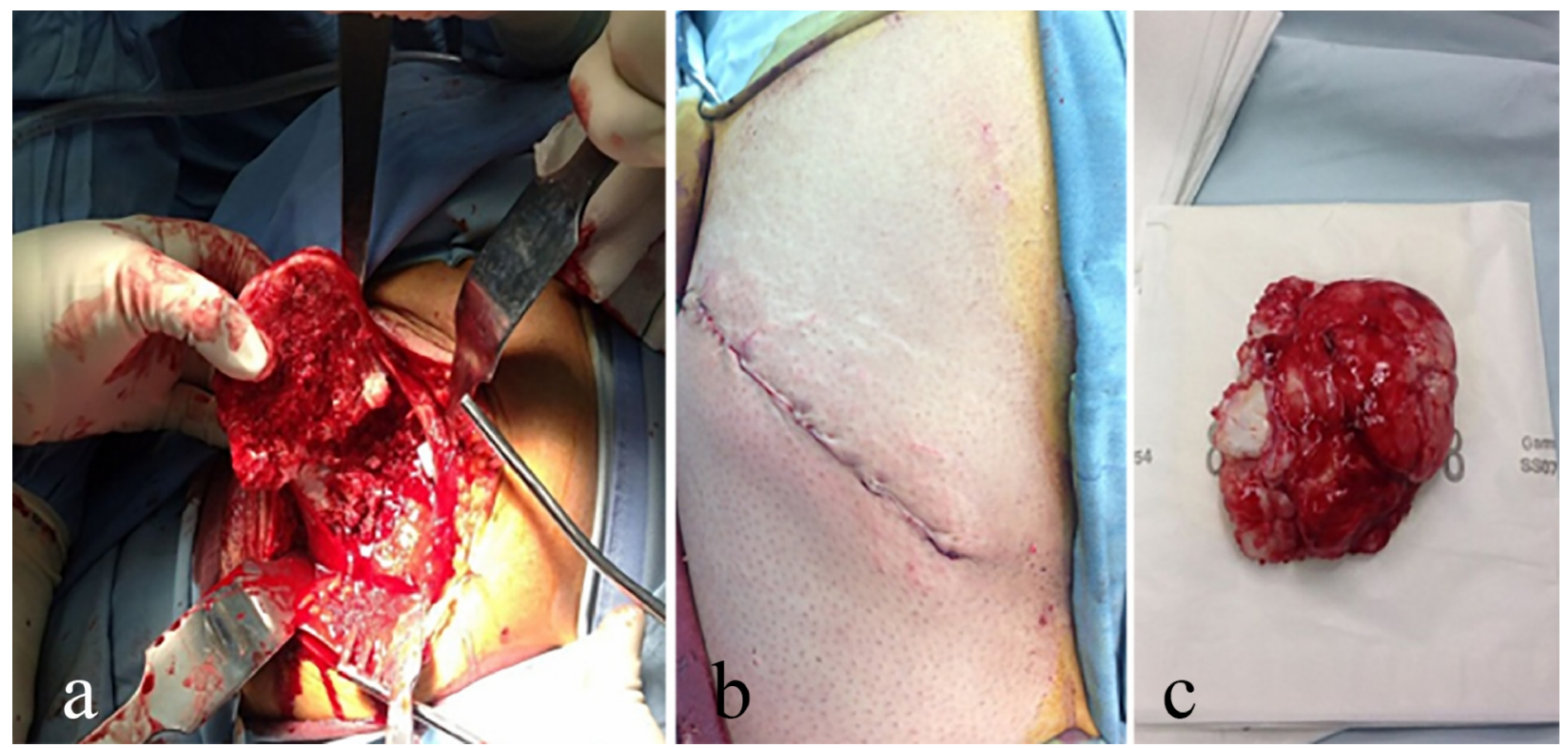

Figure 6. Showing excision of tumor (a) and closure of the incision (b) and macroscopic view of the part of tumor (c)

\section{Discussion}

The presented case has illustrated successful excision of hip osteochondromas and good outcomes in follow-up results with one-stage surgical treatment with posterior trans-gluteal approach. As we know, this case of bilateral huge hip osteochondromas has rarely been presented previously by someone who has undergone one-stage surgery 
treatment of a tumor this size.. Osteochondromas or exostoses, are the most common benign tumors of the bones, with an estimated rate of $36 \%$ in all benign bone tumors and $8.5 \%$ in all bone tumors (14). In a descriptive study in Iran, it was demonstrated that osteochondroma is the most common pathologic type of bone tumor by 35 percent (15). Osteochondromas can be solitary and multiple, as a sporadic event or secondary to traumatic insult. Multiple osteochondromas may be sporadic or familial such as HME, which is a relatively rare disease (12). The metaphyses of long bones of the extremities, knee, scapulae, vertebrae, ilium and ribs can be involved in this disorder (16). The majority of Osteochondroma masses discovered in younger patients are painless and present as slow growing mass. However, due to complications such as bone deformity, fractures, mechanical joint pain, vascular and neurological compromise and malignant transformation, significant symptoms may occur depending on the location of osteochondroma $(17,18)$. Osteochondromata of the proximal femur have been reported to occur in $30 \%$ to $90 \%$ of patients with hereditary multiple exostoses (19). Osteochondromas developing around knee and hip are usually asymptomatic but can occasionally impinge surrounding vessels and nerves, and can cause various clinical manifestations (20). Some of these clinical manifestations are femoral ante-version, impairment of hip flexion, acetabular dysplasia resulting in sublaxation of the hip, valgus deformity of the knee, and angular limb deformities (21). As in our case, the patient demonstrated symptoms including difficulty in sitting and walking. We showed that the osteochondroma of the hip originated from proximal of both femurs and sessile were a cauliflower-like mass and were huge in size. Makhdoon et al. reported three cases with osteochondroma of the hip (21). One of them was a 15year-old male presented with left hip pain and prolonged walking and sporting activities. He underwent multiple previous surgeries (left tibia, right distal femur, and upper extremities) for excision of osteochondromas. He had a Trendelenburg gait, restricted range of motion in hip abduction and flexion on examination, and left hip dysplasia and left femur neck osteochondroma causing left hip subluxation in radiography. He underwent left hip Bernese periacetabular osteotomy and femoral neck osteoplasty with partial excision of the osteochondroma through a modified Smith-Peterson approach (21). Another case was a four-year-old female with HME in the hip. She had no complaints and her examination was unremarkable apart from palpable osteochondromas in the upper extremities and distal femora. She was diagnosed by radiographs which revealed a left femoral neck osteochondroma with bilateral coxa valga, and a left dysplastic hip, and left hip subluxation. She underwent left femoral varus derotational osteotomy with partial excision of the osteochondroma through the lateral approach with application of a pediatric dynamic hip screw. She had recurrence of the left hip osteochondroma with persistent left acetabular dysplasia after 4 years, and again operated by a proximal femoral varus osteotomy and extensive excision of the left femoral neck osteochondroma through the lateral approach and a modified Dega osteotomy through a Smith-Petersen approach (21). The last case that they reported was a thirteen-year-old female known for HME who had undergone multiple previous surgeries in the lower extremities for excision of osteochondromas. She had limited flexion, abduction, and internal/external rotation and the radiographs showed bilateral acetabular dysplasia with an increased left femoral neck width secondary to osteochondromas. She underwent a left acetabular shelf procedure and femoral neck osteoplasty through the anterior approach, but the acetabular osteochondroma was not excised (21). Muzaffar et al. presented a young female with a history of hip pain for 3 years, with restriction of movements around the hip joint and radicular pain which turned out to be a solitary osteochondroma of the femoral neck that was relieved by surgical excision (22). Several surgical techniques have been reported in the previous studies and our study, which contributed the main concerns for surgical resection of femoral neck and peritrochanteric osteochondromas to exposure and femoral head vascularity. In our report, the senior author used the posterolateral approach. Rajaram Manoharan et al. (4) reported a 24 year old male patient presented with a large swelling around the right hip. Surgical excision with medial approach and lesser trochanter osteotomy was performed and at the latest follow up, the patient was pain free and there was no evidence of any recurrence. Ofiram and Porat have (23) reported a female patient (16 years old) who had an osteochondroma at the femoral neck (circumferential) and floor of acetabulum in association with acetabular dysplasia. They excised the lesion through the anterior approach with intraoperative hip subluxation. No pelvic procedure was performed, and the patient remains asymptomatic at 3 years of follow-up. Felix et al. (19) resected bilateral femoral neck osteochondromas in a 12 -year-old female patient who also had acetabular dysplasia. Bilateral staged resections, steel osteotomies, and proximal femoral varus osteotomies were performed through the posterior approach. At 3 years of follow-up, no complications were reported. Shinozaki et al. (24) resected a femoral neck osteochondroma in a 30-year-old male patient who had a dysplastic hip. The authors resected the lesion through the anterior approach and posterior approach. A rotational osteotomy was also performed. At 6 weeks of follow-up, recurrence of hip subluxation was observed and the greater trochanter was transferred distally. Siebenrock et al. (25) have described the lateral approach to the hip with surgical hip dislocation to allow access and adequate exposure of the femoral neck while preserving the vascular supply. They presented four adult patients with successful resection of femoral neck osteochondromas located in posterior, inferior, and anterior regions of the femoral neck. 


\section{Conclusions}

It is concluded that the use of different approaches in hip osteochondroma should be determined by the status of the patient, case by case, and that there is no specific approach for this condition. As we explained here, in the posterior approach used in this case, short term follow-up had a good functional outcome. As it is mentioned, there were several case reports of osteochondroma of hip joint, however they reported solitary osteochondroma of the hip and bilateral huge hip involvement is not yet reported and also in regards to surgical technique, none have been used in the one-stage surgical excision of tumor.

\section{Acknowledgments:}

We thank Erfan Hospital colleagues for their cooperation in management of the patient.

\section{Conflict of Interest:}

There is no conflict of interest to be declared.

Authors' contributions:

Both authors contributed to this project and article equally. Both authors read and approved the final manuscript.

\section{References:}

1) Albrecht S, Crutchfield JS, SeGall GK. On spinal osteochondromas. J Neurosurg. 1992; 77(2): 247-52. doi: 10.3171/jns.1992.77.2.0247. PMID: 1625013.

2) de Andrea CE, Kroon HM, Wolterbeek R, Romeo S, Rosenberg AE, DeYoung BR, et al. Interobserver Reliability in the Histopathological Diagnosis of Cartilaginous Tumors in Patients with Multiple Osteochondromas. Mod Pathol. 2012; 25(9): 1275-83. doi: 10.1038/modpathol.2012.78. PMID: 22555180.

3) Yildirim C, Rodop O, Kuskucu M, Sahin O, Gamsizkan M. Giant solitary osteochondroma arising from the fifth metatarsal bone: a case report. J Foot Ankle Surg. 2010; 49(3): 298.e9-15. doi: 10.1053/j.jfas.2010.02.024. PMID: 20605564.

4) Rajaram Manoharan S, Gopinathan N, Vishwanathan V, Goni V, Tripathy S. Surgical Excision Of A Large Sessile Osteochondroma Of The Lesser Trochanter Of Femur: A Case Report. Webmed Central. 2010; 1(11): WMC001237. doi: 10.9754/journal.wmc.2010.001237.

5) Murphey MD, Choi JJ, Kransdorf MJ, Flemming DJ, Gannon FH. Imaging of osteochondroma: variants and complications with radiologic-pathologic correlation. Radiographics. 2000; 20(5): 1407-34. doi: 10.1148/radiographics.20.5.g00se171407. PMID: 10992031.

6) Bovee J. Multiple osteochondromas. Orphanet J Rare Dis. 2008; 3(1): 3. doi: 10.1186/1750-1172-3-3. PMID: 18271966.

7) Malhotra K, Nunn T, Chandramohan M, Shanker J. Metatarsal stress fractures secondary to soft-tissue osteochondroma in the foot: case report and literature review. Foot Ankle Surg. 2011; 17(4): e51-4. doi: 10.1016/j.fas.2011.05.003. PMID: 22017915.

8) Yu K, Meehan JP, Fritz A, Jamali AA. Osteochondroma of the femoral neck: a rare cause of sciatic nerve compression. Orthopedics. 2010; 33(8). doi: 10.3928/01477447-20100625-26. PMID: 20704099.

9) Gruber-Szydlo K, Poreba R, Belowska-Bien K, Derkacz A, Badowski R, Andrzejak R, et al. Popliteal artery thrombosis secondary to a tibial osteochondroma. Vasa. 2011; 40(3): 251-5. doi: 10.1024/03011526/a000101. PMID: 21638255.

10) Mahmoodi SM, Bahirwani RK, Abdull-Gaffar BA, Habib IF. Intrabursal vein abrasion and thrombosis. An unusual complication of femoral osteochondroma. Saudi Med J. 2009; 30(12): 1604-6. PMID: 19936429.

11) Martin C, Munk PL, O'Connell JX, Lee MJ, Masri B, Wambeek N. Malignant degeneration of an osteochondroma with unusual intra-bursal invasion. Skeletal radiol. 1999; 28(9): 540-3. doi: 10.1007/s002560050560. PMID: 10525800.

12) Schmale GA, Conrad EU, 3rd, Raskind WH. The natural history of hereditary multiple exostoses. J Bone Joint Surg Am. 1994; 76(7): 986-92. doi: 10.2106/00004623-199407000-00005. PMID: 8027127.

13) Legeai-Mallet L, Munnich A, Maroteaux P, Le Merrer M. Incomplete penetrance and expressivity skewing in hereditary multiple exostoses. Clin genet. 1997; 52(1): 12-6. doi: 10.1111/j.1399-0004.1997.tb02508.x. PMID: 9272707.

14) Kitsoulis P, Galani V, Stefanaki K, Paraskevas G, Karatzias G, Agnantis NJ, et al. Osteochondromas: review of the clinical, radiological and pathological features. In Vivo. 2008; 22(5): 633-46. PMID: 18853760 . 
15) Solooki S, Vosoughi AR, Masoomi V. Epidemiology of musculoskeletal tumors in Shiraz, south of Iran. Indian J Med Paediatr Oncol. 2011; 32(4): 187-91. doi: 10.4103/0971-5851.95138. PMID: 22563150, PMCID: PMC3343243.

16) Liu W, Kong D, Tang J, Yu F. Giant costal osteochondroma in a man with multiple exostoses. Ann Thorac Surg. 2013; 96(2): 675-7. doi: 10.1016/j.athoracsur.2012.12.007. PMID: 23910108.

17) Florez B, Monckeberg J, Castillo G, Beguiristain J. Solitary osteochondroma long-term follow-up. J Pediatr Orthop B. 2008; 17(2): 91-4. PMID: 18510166.

18) Paik NJ, Han TR, Lim SJ. Multiple peripheral nerve compressions related to malignantly transformed hereditary multiple exostoses. Muscle Nerve. 2000; 23(8): 1290-4. doi: 10.1002/10974598(200008)23:8<1290::AID-MUS23>3.0.CO;2-M. PMID: 10918272.

19) Felix NA, Mazur JM, Loveless EA. Acetabular dysplasia associated with hereditary multiple exostoses. J Bone Joint Surg Br. 2000; 82(4): 555-7. PMID: 10855881.

20) Tanigawa N, Kariya S, Kojima H, Komemushi A, Fujii H, Sawada S. Lower limb ischaemia caused by fractured osteochondroma of the femur. Br J Radiol. 2007; 80(952): e78-80. doi: 10.1259/bjr/44678280.

21) Makhdom AM, Jiang F, Hamdy RC, Benaroch TE, Lavigne M, Saran N. Hip Joint Osteochondroma: Systematic Review of the Literature and Report of Three Further Cases. Adv Orthop. 2014; 2014: 180254. doi: 10.1155/2014/180254. PMID: 24963411.

22) Muzaffar N, Bashir N, Baba A, Ahmad A, Ahmad N. Isolated osteochondroma of the femoral neck presenting as hip and leg pain. A case study. Ortop Traumatol Rehabil. 2012; 14(2): 183-7. doi: 10.5604/15093492.992290. PMID: 22619103.

23) Ofiram E, Porat S. Progressive subluxation of the hip joint in a child with hereditary multiple exostosis. J Pediatr Orthop B. 2004; 13(6): 371-3. doi: 10.1097/01202412-200411000-00004. PMID: 15599227.

24) Shinozaki $T$, Watanabe $H$, Inoue J, Ogiwara $T$. Rotational acetabular osteotomy in a dysplastic hip with femoral neck osteochondromas. Orthopedics. 1998; 21(5): 588-90. PMID: 9606700.

25) Siebenrock KA, Ganz R. Osteochondroma of the Femoral Neck. Clin Orthop Relat Res. 2002; 394: 211-8. doi: 10.1097/00003086-200201000-00025. PMID: 11795736. 